\title{
Overexpression of histone deacetylase 6 contributes to accelerated migration and invasion activity of hepatocellular carcinoma cells
}

\author{
KIMINORI KANNO ${ }^{1,2,3}$, SHOJI KANNO ${ }^{2}$, HIROYUKI NITTA ${ }^{2}$, NORIYUKI UESUGI ${ }^{4}$, TAMOSTU SUGAI ${ }^{4}$, \\ TOMOYUKI MASUDA $^{3}$, GO WAKABAYASHI $^{2}$ and CHIHAYA MAESAWA ${ }^{1}$ \\ ${ }^{1}$ Department of Tumor Biology, Institute of Biomedical Science, and Departments of ${ }^{2}$ Surgery and \\ ${ }^{3}$ Pathology, School of Medicine, Iwate Medical University, Morioka; ${ }^{4}$ Division of Diagnostic Molecular \\ Pathology, Department of Pathology, School of Medicine, Iwate Medical University, Morioka, Japan
}

Received February 25, 2012; Accepted May 18, 2012

DOI: $10.3892 /$ or.2012.1898

\begin{abstract}
Histone deacetylase 6 (HDAC6) is a cytoplasmic enzyme that regulates many important biological processes, including cell migration, viral infection and autophagy. The aim of this study was to investigate the significance of HDAC6 in the invasion and metastasis activities of hepatocellular carcinoma (HCC). Three HCC cell lines and two primary cultures of hepatocytes were used for biological experiments. Immunohistochemistry for HDAC6 protein was also examined in 70 resected primary HCCs. Knockdown of the HDAC6 gene in the HCC cell lines was carried out by treatment with siRNA, and their migration and invasion activities were examined by the scratch assay and Matrigel invasion assay, respectively. HDAC6 expression was greater in all of the HCC cell lines compared to the primary cultures of hepatocytes. Knockdown of HDAC6 markedly downregulated the migration and invasion activities of all HCC cell lines $(\mathrm{P}<0.05)$. Overexpression of HDAC6 protein to a level higher than that in the corresponding normal hepatocytes was observed in $14(20 \%)$ of the 70 primary HCCs, and was significantly correlated with high clinical stage, number of tumors, vascular invasion and intrahepatic metastasis $(\mathrm{P}<0.05)$. These results suggest that overexpression of the HDAC6 protein is involved in the migration and invasion activities of HCC cells, and may be a good biomarker for prediction of intrahepatic metastasis.
\end{abstract}

\section{Introduction}

Hepatocellular carcinoma (HCC) is the fifth most common malignancy worldwide and causes nearly one million deaths a year (1). Despite the development of several modalities for

Correspondence to: Dr Chihaya Maesawa, Department of Tumor Biology, Institute of Biomedical Science, Iwate Medical University, 2-1-1 Nishitokuta, Yahaba-cho, Morioka 028-3694, Japan

E-mail: chihaya@iwate-med.ac.jp

Key words: hepatocellular carcinoma, migration, invasion, intrahepatic metastasis, HDAC6 the treatment of HCC (2-7), including transcatheter arterial embolization, percutaneous ablation, surgical resection, liver transplantation and molecular targeted medicine, the prognosis of patients with HCC still remains relatively poor. One of the major factors responsible for these unsatisfactory outcomes is the high frequency of intrahepatic recurrence after curative treatment $(5,8)$. Intrahepatic recurrence is the result of two mechanisms: intrahepatic metastasis originating from the primary cancer, and a second primary cancer arising through multicentric carcinogenesis. Intrahepatic metastasis may correlate with early recurrence and poor prognosis, whereas multicentric carcinogenesis is associated with a relatively good prognosis (9-11). With the aim of controlling intrahepatic recurrence of $\mathrm{HCC}$, various studies have investigated the molecular mechanisms underlying intrahepatic metastasis (12-17), which frequently occurs at an advanced disease stage, presumably through tumor cell dispersal via the portal vein; there is a strong statistical correlation between the presence of intrahepatic metastasis and the frequency of vascular invasion (18).

Tumor invasiveness may be considered a phenomenon of cell motility. In fact, tumor cell motility plays a central role in carcinoma cell dissemination, and the cytoskeleton, a key structure of the cell machinery, is continuously remodeled during cell movement. In this context, several molecules related to the microtubule (MT)- and actin-dependent dynamics of tumor cells have been investigated as possible predictors of intrahepatic metastasis of HCCs, or targets of preventive therapy. Highly dynamic MTs are distributed randomly throughout the cell periphery, and the less dynamic ones are located between the nucleus and the leading edge of the cell (19). A previous study has revealed that overexpression of HDAC6 increases cell motility, suggesting that deacetylation of at least one cytoplasmic HDAC protein enhances motility (20). It has also been shown that in HDAC6-inhibited cells, MT dynamics are decreased, leading to an increase of focal adhesion accumulation, and thus a decrease in cell motility (21). Moreover, HDAC6 protein can also interact with a different substrate, cortactin, in vivo and in vitro, and both HDAC6 catalytic domains are necessary for the interaction. Cortactin is an acetylated protein found in areas of dynamic actin assembly, such as the leading edge of migrating cells 
(22). This protein was originally identified as a substrate of Src tyrosine kinase, and plays a role in regulating cell motility. Disruption of HDAC6 leads to hyperacetylation of cortactin and prevents its translocation to the cell periphery, blocks association with F-actin, and impairs cell motility (23). We recently demonstrated that disruption of the HDAC6/NACC1 (nucleus accumbens associated 1) deacetylation system markedly downregulated cell motility through MT and cortactin deacetylation (24). Thus, HDAC6 may act as a mediator between actin- and tubulin-associated proteins to regulate cell motility.

Although overexpression of HDAC6 and its relationship with invasion and metastasis have been documented in several malignancies (24-26), it has not been documented in HCCs. The present study examined the expression of HDAC6 in HCC cultured cells and primary tumors, and investigated its association with migration and invasion activities in vitro and in vivo.

\section{Materials and methods}

Cell culture. HCC cell lines were obtained from HSRRB (Health Science Research Resources Bank, Osaka, Japan; HLF, PLC/PRF/5) and IDAC (Institute of Department, Aging and Cancer, Tohoku University, Sendai, Japan; Hep3B). Two human normal hepatocyte cell lines, Hc-cells (Applied Cell Biology Research Institute, Human Hepatocyte Cell culture \#3716, Kirkland, WA, USA) and WRL-68 (American Type Culture Collection, Rockville, MD, USA), were obtained commercially and maintained under the recommended conditions.

Surgical specimens and immunohistochemistry. Immunohistochemistry for HDAC6 protein expression was performed on tumor samples from 70 patients with HCC treated between 2006 and 2011 at the Department of Surgery, School of Medicine, Iwate Medical University, Morioka, Japan. The patient characteristics are summarized in Table I. Permission for the study was obtained from the Institutional Review Board (School of Medicine, Iwate Medical University, Morioka, Japan) and written consent was obtained from all patients before surgery.

Surgical specimens were fixed in $10 \%$ buffered formalin solution and embedded in paraffin wax, and two or more blocks were made for immunohistochemistry. Sections $4 \mu \mathrm{m}$ thick were cut, and stained with hematoxylin and eosin. Serial sections were stained with the avidin-biotin system on a Ventana automated immunostainer with the Ventana immunohistochemistry detection system (Ventana Medical Systems, Tucson, AZ, USA), in accordance with the manufacturer's manual. An anti-HDAC6 antibody (H-300, diluted 1:100, Santa Cruz Biotechnology, Santa Cruz, CA, USA) was used as the primary antibody.

Western blotting. All cell lines were cultured to 70-80\% confluence on 10-cm Petri dishes. Cold PBS was added, and the cells were removed from the dishes by scraping. After removal of the supernatants, the cell pellet was dissolved in cell lysis buffer [50 mM Tris- $\mathrm{HCl}$, pH 8.0/150 mM NaCl/1 mM EDTA, $\mathrm{pH} 8.0 / 1 \%$ Triton $\mathrm{X}-100 / 0.1 \%$ sodium deoxycholate/0.1\%
Table I. Characteristics of 70 patients with hepatocellular carcinoma.

\begin{tabular}{|c|c|}
\hline Factor & No. of patients $(\%)$ \\
\hline \multicolumn{2}{|l|}{ Gender } \\
\hline Male & $52(74)$ \\
\hline Female & $18(26)$ \\
\hline \multicolumn{2}{|l|}{ Age (years) } \\
\hline Mean (range) & $64.2(39-81)$ \\
\hline$<65$ & $33(47)$ \\
\hline$\geq 65$ & $37(53)$ \\
\hline \multicolumn{2}{|l|}{ Clinical stage } \\
\hline I & $9(13)$ \\
\hline II & $31(45)$ \\
\hline III & $26(38)$ \\
\hline IVA & $4(4)$ \\
\hline \multicolumn{2}{|l|}{ No. of tumors } \\
\hline Single & $50(71)$ \\
\hline Multiple & $20(29)$ \\
\hline \multicolumn{2}{|c|}{ Tumor diameter $(\mathrm{cm})$} \\
\hline$<3$ & $24(35)$ \\
\hline$\geq 3$ & $46(65)$ \\
\hline \multicolumn{2}{|c|}{ Lymph node status } \\
\hline Yes & $2(3)$ \\
\hline None & $68(97)$ \\
\hline \multicolumn{2}{|l|}{ Virus infection } \\
\hline $\mathrm{HBV}$ & $28(40)$ \\
\hline $\mathrm{HCV}$ & $21(30)$ \\
\hline $\mathrm{HBV}+\mathrm{HCV}$ & $1(1)$ \\
\hline Non infection & $20(29)$ \\
\hline \multicolumn{2}{|c|}{ Vascular invasion } \\
\hline Presence & $20(28)$ \\
\hline Absence & $50(72)$ \\
\hline \multicolumn{2}{|c|}{ Intrahepatic metastasis } \\
\hline Presence & $19(27)$ \\
\hline Absence & $51(73)$ \\
\hline
\end{tabular}

SDS/1 mM PMSF/10 mM NaF/2 $\mathrm{mM} \mathrm{Na}_{3} \mathrm{VO}_{4} / 1 \mathrm{X}$ protease inhibitor complete (Roche Diagnostics GmbH, Mannheim, Germany)]. Cell samples containing equal amounts of protein were mixed with $5 \mathrm{X}$ sample buffer, and heated for $5 \mathrm{~min}$ at $95^{\circ} \mathrm{C}$. Protein was electrophoresed on $4-12 \% \mathrm{Nu}-\mathrm{PAGE}$ for $45 \mathrm{~min}$ at $200 \mathrm{~V}$ constant voltage, and then transferred onto polyvinylidene difluoride membranes (Invitrogen, Carlsbad, CA, USA) for $1 \mathrm{~h}$ at $30 \mathrm{~V}$ constant voltage. Membranes were blocked with $5 \%$ blocking reagent (Cell Signaling Technology, Danvers, MA, USA) in 1X Tris-buffered saline/Tween-20 buffer for $1 \mathrm{~h}$ at room temperature, and immunostained overnight with a primary antibody (HDAC6 H-300, diluted 1:250, Santa Cruz Biotechnology) at $4^{\circ} \mathrm{C}$. The membranes were then rinsed with Tris-buffered saline/Tween-20 and incubated with horseradish HRP-conjugated secondary antibodies [anti-rabbit 
or-mouse IgG (diluted 1:5,000, GE Healthcare, Little Chalfont, $\mathrm{UK})$ ] for $1 \mathrm{~h}$ at room temperature. Signals were detected with ECL Prime (GE Healthcare) and ChemiDoc XRS (Bio-Rad Laboratories, Hercules, CA, USA). The intensity of the detected signals was measured using 1-D analysis software (Quantity One, Bio-Rad Laboratories). For normalization of the target, glyceraldehyde-3-phosphate dehydrogenase (GAPDH, diluted 1:100; Covance, Princeton, NJ, USA) was used as an internal control.

RNA isolation and reverse transcriptase quantitative PCR. Total RNA was extracted with TRIzol reagent (Invitrogen), and transcribed to cDNA using a SuperScript III first-strand synthesis system (Invitrogen). For quantitative evaluation of relevant mRNAs, we used Custom TaqMan Gene Expression assays (HDAC6, Hs00195869_ m1; Invitrogen), and an ABI PRISM 7500 instrument (Invitrogen). For normalization of the target, GAPDH (Invitrogen) was used as an internal control. All reactions (each containing 3 templates) were run in triplicate, and average fold differences were calculated by normalizing the relative expression ( $\Delta \Delta \mathrm{Ct}$ values) according to ABI User Bulletin \#2.

siRNA knockdown of the HDAC6 gene. For silencing of HDAC6 gene mRNA, three predesigned HDAC6-specific siRNA sequences (\#1, s19459; \#2, s19760; \#3, s19461; Silencer Select siRNA, Invitrogen), and control non-specific human siRNAs (Silencer Select Pre-designed siRNA Negative Control \#1, 4390843; \#2, 4390844, Invitrogen) were used. siRNA transfection was performed using Lipofectamine RNAiMAX Reagent (Invitrogen) in accordance with the manufacturer's instructions.

Scratch assay. Confluent monolayer cells were scratched to create a wound, and then 0,24 and $48 \mathrm{~h}$ later, three different fields of each wound were photographed with a phase-contrast microscope. Three independent experiments were performed. Measurements of the width of each wound were performed under each experimental condition. At the start of the experiment, the wound size was measured and scored as $100 \%$. After 24 and $48 \mathrm{~h}$, the width of the residual wound was measured and the average percentage of wound closure was calculated by using the free web software ImageJ (http://rsb.info.nih. gov/ij).

Matrigel invasion assay. The cell invasion assay was performed using a BioCoat Matrigel invasion chamber (Becton-Dickinson, Bedford, MA, USA) in accordance with the protocol provided by the manufacturer. After cells in logphase growth had been incubated with serum-free medium for $12 \mathrm{~h}$, they were detached using trypsin-EDTA. Resuspended cells were added to each chamber at a density of $5 \times 10^{4}$ cells in $500 \mu \mathrm{l}$, and allowed to invade the Matrigel for $24 \mathrm{~h}$ at $37^{\circ} \mathrm{C}$ under a $5 \% \mathrm{CO}_{2}$ atmosphere. Cells that had not penetrated the filter were wiped out with cotton swabs, and cells that had migrated to the lower surface of the filter were stained with Quick-Diff stain kit (Symex International Reagents, Co., Ltd., Hyogo, Japan). After two washes with water, the chambers were allowed to air-dry, and the number of invading cells was counted using a light microscope. The degree of invasion was

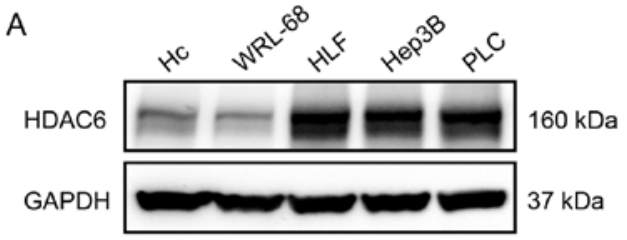

B

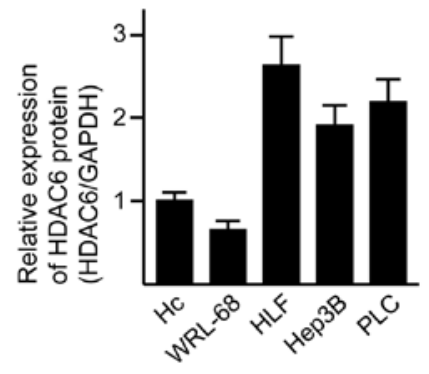

C

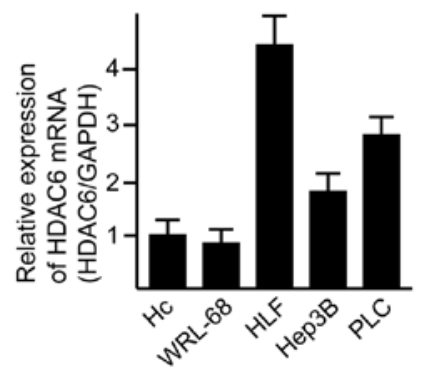

Figure 1. Expression of HDAC6 mRNA/protein in three hepatocellular carcinoma cell lines (HLF, Hep3B and PLC) and two primary cultures of hepatocytes (Hc and WRL-68). (A) Western blotting for HDAC6 protein. Equal loading was confirmed by blotting GAPDH. Quantitative results of western blotting (B) and RT-PCR (C) for HDAC6.

expressed as the average number of migrated cells bound per microscopic field over four fields per assay, and as averages for triplicate experiments.

Statistical analysis. All data are presented as means \pm standard error. Correlations between HDAC6 protein expression and clinicopathological data were analyzed by Fisher's exact test or Kruskal-Wallis test. Mann-Whitney U test for non-parametric samples was used for analyses of biological experimental data. The level of significance was considered to be $\mathrm{P}<0.05$.

\section{Results}

Expression of the HDAC6 gene in cell lines and efficiency of knockdown by treatment with siRNA. We first examined HDAC6 mRNA/protein expression in three HCC cell lines and two primary-cultured normal hepatocyte lines (Fig. 1). Under the recommended culture conditions at $60-70 \%$ confluency, all of the HCC cell lines exhibited overexpression of HDAC6 mRNA/protein in comparison with normal hepatocytes (Fig. 1). We evaluated the knockdown efficiency of HDAC6siRNAs (\#1, \#2 and \#3; $10 \mathrm{nM}$ ) in one HCC cell line (PCL, Fig. 2). In comparison with negative control siRNA, all the siRNAs caused $80-90 \%$ downregulation of HDAC6 expression (Fig. 2). 
A

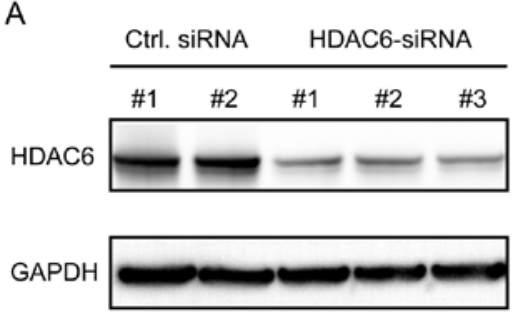

B

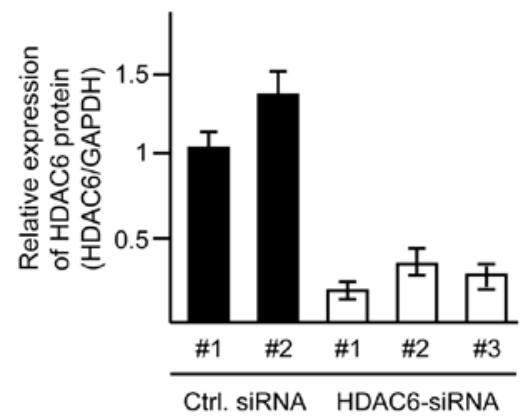

Figure 2. Effects of siRNA transfection on HDAC6 protein expression in a hepatocellular carcinoma cell line (PLC). Immunoblotting (A) for HDAC6 protein and its quantification (B) at $48 \mathrm{~h}$ after siRNA transfection.
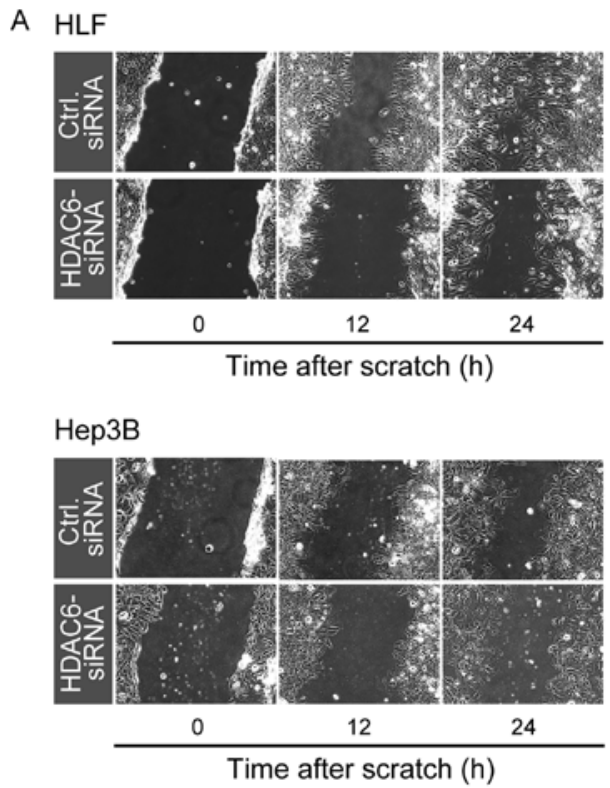

PLC

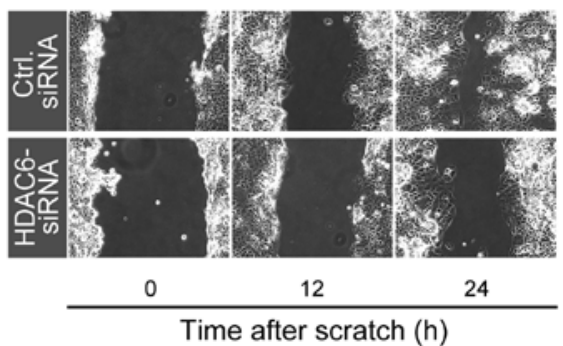

B
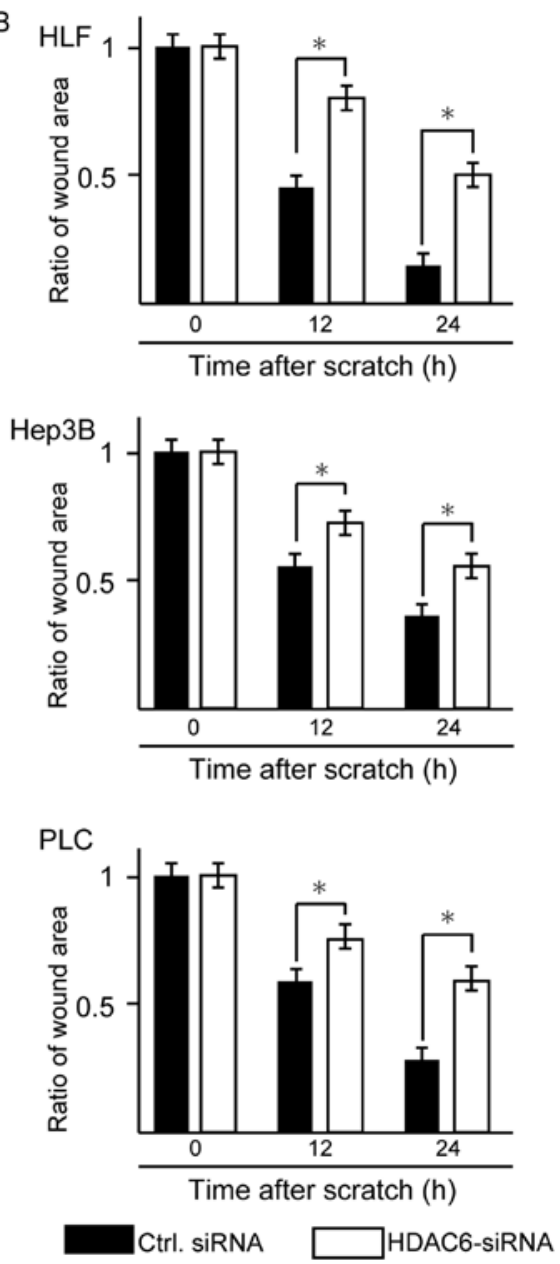

Figure 3. Migration activity induced by treatment with HDAC6-siRNA (10 nM) in hepatocellular carcinoma cell lines. (A) Photographs of scratch assays for hepatocellular carcinoma cell lines at $48 \mathrm{~h}$ after transfection with control or HDAC6-siRNA (10 nM). (B) Quantitative results at 12 and $24 \mathrm{~h}$ after scratching. Cell migration activity (inversely correlated with the wound area ratio) was significantly decreased in cells treated with $H D A C 6$-siRNA. Average values from triplicate wells are shown. ${ }^{*} \mathrm{P}<0.05$. Ctrl., control.

Migration and invasion activities induced by treatment with HDAC6-siRNA in HCC cell lines. Using \#1 HDAC6-siRNA, we then examined the migration activities of the three HCC cell lines by the scratch assay. HDAC6 knockdown significantly decreased tumor cell migration activities of all three lines in comparison with the negative control at 24 and $48 \mathrm{~h}$ ( $\mathrm{P}<0.05$, Mann-Whitney U-test; Fig. 3). To determine whether HDAC6 knockdown decreased the invasiveness of HCC cells, we performed the Matrigel invasion assay. Treatments with HDAC6-siRNA significantly suppressed the invasiveness of all HCC cell lines in comparison with control siRNA treatment (Fig. 4).

Immunohistochemistry of HDAC6 protein, and relationship between HDAC6 expression and clinicopathological variables in primary HCCs. We immunohistochemically examined 


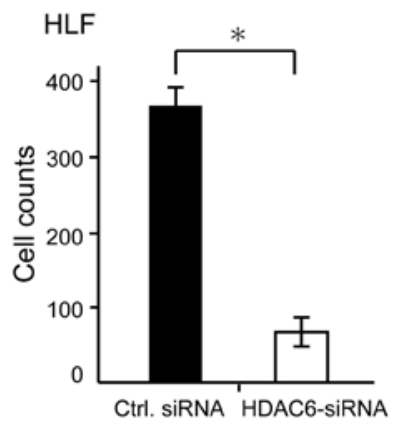

Hep3B
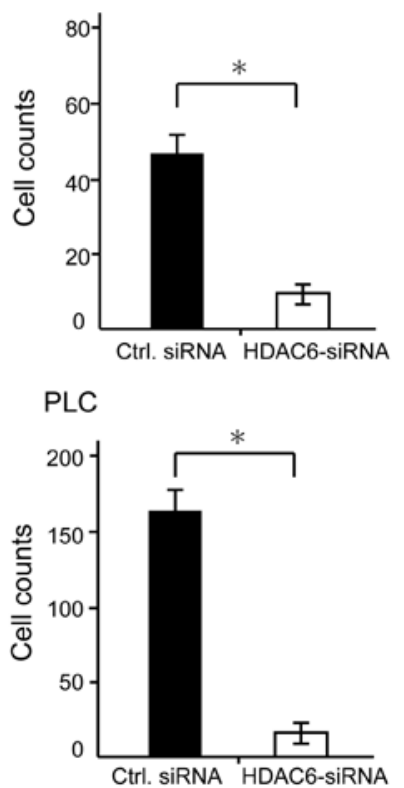

Figure 4. Invasion activity induced by treatment with HDAC6-siRNA $(10 \mathrm{nM})$ in hepatocellular carcinoma cell lines. Quantitative results of the Matrigel invasion assay are shown. Cells transfected with HDAC6 or control (Ctrl.) siRNA $(10 \mathrm{nM})$ were disseminated in the 24-well Matrigel plate, and the number of cells in the bottom chamber was counted at $48 \mathrm{~h}$ after dissemination. A significant decrease of cell number was observed in HDAC6-knockdown cells as compared with the control in hepatocellular carcinoma cell lines treated with HDAC6-siRNA at 24 and $48 \mathrm{~h}$. Average values from triplicate wells are shown.

HDAC6 protein expression in 70 patients with primary HCCs. Two independent pathologists performed the assessment of immunohistochemical staining. Immunoreactivity for HDAC6 was diffusely positive in both tumor cells and surrounding normal hepatocytes. Overexpression of HDAC6 protein to a level higher than that in the corresponding normal hepatocytes was observed in 14 (20\%, Fig. 5C) of the 70 primary HCCs. Lower immunoreactivity for HDAC6 protein was found in 21 (30\%, Fig. 5A) of the 70, and the remaining 35 (50\%, Fig. 5B) exhibited immunoreactivity equal to that of the corresponding normal hepatocytes. Table II summarizes the relationship between HDAC6 immunoreactivity and clinicopathological variables in all cases. Overexpression of HDAC6 protein was significantly correlated with high clinical stage, number of tumors, vascular invasion, and intrahepatic metastasis $(\mathrm{P}<0.05)$ (Table II).

\section{Discussion}

Several growth factors and cytokines such as transforming growth factor (27), platelet-derived growth factor (28), epidermal growth factor (29), hepatocyte growth factor (30), and extracellular matrix (31) secreted into the microenvironment surrounding tumor cells are involved in their migration and invasion. These secreted proteins and their related intracellular signaling cascades induce epithelial mesenchymal transition and accelerate the migration/invasion activity of $\mathrm{HCC}$, resulting in intrahepatic metastasis. Moreover, several adhesion molecules and their related proteins such as E-cadherin, ROCK2 and CD24 also are involved (32-34). Apart from proteins secreted into the microenvironment of tumor cells and adhesion molecules, transcriptional factors such as $p 300$ and Snail $(35,36)$ also contribute to the acquisition of metastatic potential by HCC cells. Our present study showed that overexpression of HDAC6, which affects both MT- and actin-dependent cell migration mechanisms, contributed to acceleration of migration/invasion activity in HCC cell lines in vitro and in vivo. In particular, the results of immunostaining of primary HCCs were well correlated with intrahepatic metastasis. HDAC6 was thus suggested to be a newly characterized key player in the control of intrahepatic metastasis.

HDAC6 is a unique protein of the histone deacetylase family, and can affect the function of cytoplasmic non-histone proteins. It is a key regulator of many aspects of cancer biology such as the cell cycle, cell migration, drug resistance and autophagy, thereby making HDAC6 an attractive target for cancer therapy (37). Although HDAC6 protein is expressed in the liver as well as the heart, kidney, testis, brain, and pancreas
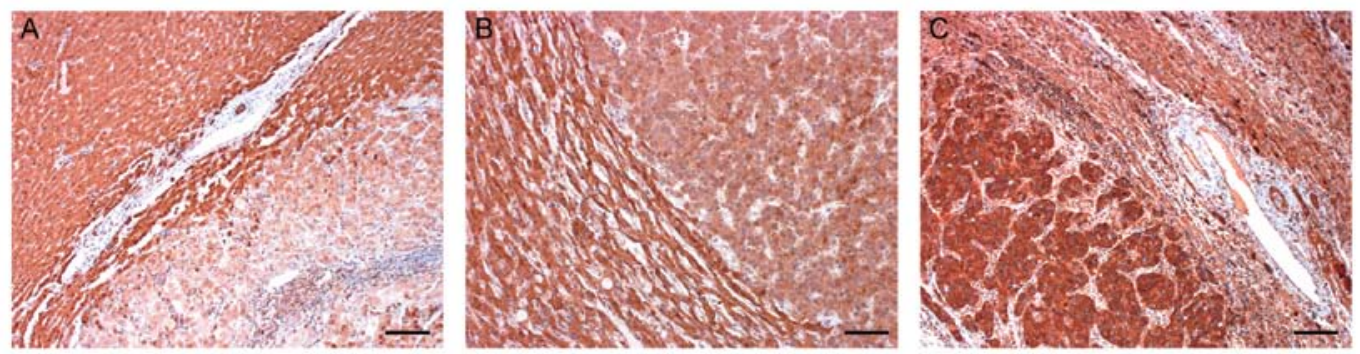

Figure 5. Immunohistochemistry for HDAC6 protein in primary hepatocellular carcinomas. (A) Lower immunoreactivity for HDAC6 protein in comparison with the corresponding normal hepatocytes (1+), (B) exhibiting immunoreactivity equal to that of the corresponding normal hepatocytes $(2+)$, and (C) overexpression to a level higher than that in the corresponding normal hepatocytes $(3+)$. Bars, $100 \mu \mathrm{m}$. 
Table II. Clinicopathological variables of patients according to HDAC6 expression.

\begin{tabular}{|c|c|c|c|c|}
\hline \multirow[b]{2}{*}{ Factor } & \multirow[b]{2}{*}{ No. of patients } & \multicolumn{2}{|c|}{ Immunoreactivity of HDAC6 } & \multirow[b]{2}{*}{ P-value } \\
\hline & & $0,+1,+2(\%)$ & $+3(\%)$ & \\
\hline \multicolumn{5}{|l|}{ Gender } \\
\hline Male & 52 & $42(60)$ & $10(14)$ & $0.513^{\mathrm{a}}$ \\
\hline Female & 18 & $14(20)$ & $4(6)$ & \\
\hline \multicolumn{5}{|l|}{ Age (years) } \\
\hline$<65$ & 33 & $27(39)$ & $6(9)$ & $0.719^{\mathrm{a}}$ \\
\hline$\geq 65$ & 37 & $29(41)$ & $8(11)$ & \\
\hline \multicolumn{5}{|l|}{ Clinical stage } \\
\hline $\mathrm{I}, \mathrm{II}$ & 40 & $36(51)$ & $4(6)$ & $0.017^{\mathrm{a}}$ \\
\hline III, IV & 30 & $20(29)$ & $10(14)$ & \\
\hline \multicolumn{5}{|l|}{ No. of tumors } \\
\hline Single & 50 & $43(62)$ & $7(10)$ & $0.047^{\mathrm{a}}$ \\
\hline Multiple & 20 & $13(18)$ & $7(10)$ & \\
\hline \multicolumn{5}{|c|}{ Tumor diameter $(\mathrm{cm})$} \\
\hline$<3$ & 24 & $20(29)$ & $4(6)$ & $0.433^{\mathrm{a}}$ \\
\hline$\geq 3$ & 46 & $36(51)$ & $10(14)$ & \\
\hline \multicolumn{5}{|l|}{ Virus infection } \\
\hline $\mathrm{HBV}$ & 28 & $22(31)$ & $6(9)$ & $0.960^{\mathrm{b}}$ \\
\hline $\mathrm{HCV}$ & 21 & $17(24)$ & $4(6)$ & \\
\hline $\mathrm{HBV}+\mathrm{HCV}$ & 1 & $1(1)$ & $0(0)$ & \\
\hline No infection & 20 & $6(9)$ & $14(20)$ & \\
\hline \multicolumn{5}{|c|}{ Vascular invasion } \\
\hline Presence & 20 & $12(17)$ & $8(11)$ & $0.008^{\mathrm{a}}$ \\
\hline Absence & 50 & $44(63)$ & $6(9)$ & \\
\hline \multicolumn{5}{|c|}{ Intrahepatic metastasis } \\
\hline Presence & 19 & $12(17)$ & $7(10)$ & $0.031^{\mathrm{a}}$ \\
\hline Absence & 51 & $44(63)$ & $7(10)$ & \\
\hline
\end{tabular}

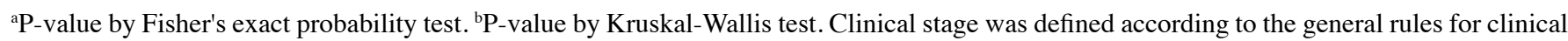
and pathological study of primary liver cancer (June. 2009; Liver Cancer Study group of Japan).

(38), there has been little information about the significance of HDAC6 in HCC tumorigenesis. It is well known that HDAC inhibitors, such as TSA and SAHA, block invasive cell motility, and therefore it is anticipated that they might be applicable for control of intrahepatic metastasis. However, most of these molecules act by altering gene expression via hyperacetylated HDAC nuclear substrates, such as histones or transcription factors, and the spectrum of targeted molecules is broad. Therefore, development of inhibitors that are more selective in targeting intrahepatic metastasis is warranted. An HDAC6 inhibitor known as tubacin (tubulin acetylation inducer) was isolated through a multidimensional chemical genetic screen of 7,392 small molecules and a cell-based assay targeting the acetylation activity of proteins other than histones $(39,40)$. Unlike other histone deacetylase inhibitors, tubacin was found to inhibit the deacetylation of MT in mammalian cells without affecting the level of histone acetylation, gene expression, or cell cycle progression $(13,14)$. Furthermore, using scratch assay and trans-Matrigel migration assays, another group has demonstrated that NK84-mediated inhibition of HDAC6 in ovarian cancer cell lines retarded cell spreading and inhibited cell migration, respectively (41). Recently, the effectiveness of combination therapy using an HDAC6-selective inhibitor (ACY-1215) and bortezomib has been demonstrated in a preclinical trial (42). Thus, a new class of agents targeting HDAC6 is currently being developed, and their efficacy is being tested.

The functions of HDAC6 in cell migration/invasion activity may depend on decacetylation activity targeting $\alpha$-tubulin and cortactin. Both proteins are also deacetylated by $S I R T 2$, which belongs to another class of the histone deacetylase family. Using SIRT2-specific siRNA combined with tubacin treatment, Zuo et al (25) have demonstrated that cell migratory and invasive abilities can be dramatically suppressed. Moreover, SIRT2-deficient mice show gender-specific tumorigenesis, females primarily developing mammary tumors, and males developing more HCCs (43). The significance of SIRT2 should therefore be examined in human HCC tumorigenesis, including its relationship with intrahepatic metastasis. 


\section{Acknowledgements}

This study was supported in part by Grants-in-Aid for Scientific Research (22390071), the MIAST project, and a Grant-in-Aid for Strategic Medical Science Research from the Ministry of Education, Culture, Sports, Science and Technology of Japan.

\section{References}

1. Jemal A, Siegel R, Xu J and Ward E: Cancer statistics, 2010. CA Cancer J Clin 60: 277-300, 2010.

2. Takahara T, Nitta H, Hasegawa Y, Itou N, Takahashi M and Wakabayashi G: Using sorafenib for recurrent hepatocellular carcinoma after liver transplantation - interactions between calcineurin inhibitor: two case reports. Transplant Proc 43: 2800-2805, 2011.

3. Nitta H, Sasaki A, Fujita T, et al: Laparoscopy-assisted major liver resections employing a hanging technique: the original procedure. Ann Surg 251: 450-453, 2010.

4. Sasaki A, Nitta H, Otsuka K, Takahara T, Nishizuka S and Wakabayashi G: Ten-year experience of totally laparoscopic liver resection in a single institution. Br J Surg 96: 274-279, 2009.

5. Llovet JM, Burroughs A and Bruix J: Hepatocellular carcinoma. Lancet 362: 1907-1917, 2003.

6. Salhab M and Canelo R: An overview of evidence-based management of hepatocellular carcinoma: a meta-analysis. J Cancer Res Ther 7: 463-475, 2011.

7. Thomas MB, Jaffe D, Choti MM, et al: Hepatocellular carcinoma: consensus recommendations of the National Cancer Institute Clinical Trials Planning Meeting. J Clin Oncol 28: 3994-4005, 2010.

8. Izumi N, Asahina Y, Noguchi O, et al: Risk factors for distant recurrence of hepatocellular carcinoma in the liver after complete coagulation by microwave or radiofrequency ablation. Cancer 91 : 949-956, 2001

9. Poon RT, Fan ST, Ng IO, Lo CM, Liu CL and Wong J: Different risk factors and prognosis for early and late intrahepatic recurrence after resection of hepatocellular carcinoma. Cancer 89: 500-507, 2000

10. Arii S, Monden K, Niwano M, et al: Results of surgical treatment for recurrent hepatocellular carcinoma; comparison of outcome among patients with multicentric carcinogenesis, intrahepatic metastasis, and extrahepatic recurrence. J Hepatobiliary Pancreat Surg 5: 86-92, 1998.

11. Miyata R, Tanimoto A, Wakabayashi G, et al: Accuracy of preoperative prediction of microinvasion of portal vein in hepatocellular carcinoma using superparamagnetic iron oxide-enhanced magnetic resonance imaging and computed tomography during hepatic angiography. J Gastroenterol 41: 987-995, 2006.

12. Ma WL, Hsu CL, Yeh CC, et al: Hepatic androgen receptor suppresses hepatocellular carcinoma metastasis through modulation of cell migration and anoikis. Hepatology: Feb 9, 2012 (Epub ahead of print).

13. Yamazaki K, Masugi Y and Sakamoto M: Molecular pathogenesis of hepatocellular carcinoma: altering transforming growth factor-beta signaling in hepatocarcinogenesis. Dig Dis 29: 284-288, 2011

14. Zheng F, Liao YJ, Cai MY, et al: The putative tumour suppressor microRNA-124 modulates hepatocellular carcinoma cell aggressiveness by repressing ROCK2 and EZH2. Gut 61: 278-289, 2012.

15. Fu J, Chen Y, Cao J, et al: p28(GANK) overexpression accelerates hepatocellular carcinoma invasiveness and metastasis via phosphoinositol 3-kinase/AKT/hypoxia-inducible factor-1alpha pathways. Hepatology 53: 181-192, 2012.

16. Yao J, Liang L, Huang S, et al: MicroRNA-30d promotes tumor invasion and metastasis by targeting Galphai 2 in hepatocellular carcinoma. Hepatology 51: 846-856, 2010.

17. Mazzocca A, Liotta F and Carloni V: Tetraspanin CD81regulated cell motility plays a critical role in intrahepatic metastasis of hepatocellular carcinoma. Gastroenterology 135: 244-256, 2008.

18. Sakon M, Nagano H, Nakamori S, et al: Intrahepatic recurrences of hepatocellular carcinoma after hepatectomy: analysis based on tumor hemodynamics. Arch Surg 137: 94-99, 2002.
19. Gundersen GG and Bulinski JC: Selective stabilization of microtubules oriented toward the direction of cell migration. Proc Natl Acad Sci USA 85: 5946-5950, 1988.

20. Hubbert C, Guardiola A, Shao R, et al: HDAC6 is a microtubuleassociated deacetylase. Nature 417: 455-458, 2002.

21. Tran AD, Marmo TP, Salam AA, et al: HDAC6 deacetylation of tubulin modulates dynamics of cellular adhesions. J Cell Sci 120: 1469-1479, 2007.

22. Wu H and Parsons JT: Cortactin, an 80/85-kilodalton pp60src substrate, is a filamentous actin-binding protein enriched in the cell cortex. J Cell Biol 120: 1417-1426, 1993.

23. Luxton GW and Gundersen GG: HDAC6-pack: cortactin acetylation joins the brew. Dev Cell 13: 161-162, 2007.

24. Tsunoda K, Oikawa H, Tada H, et al: Nucleus accumbens-associated 1 contributes to cortactin deacetylation and augments the migration of melanoma cells. J Invest Dermatol 131: 1710-1719, 2011.

25. Zuo Q, Wu W, Li X, Zhao L and Chen W: HDAC6 and SIRT2 promote bladder cancer cell migration and invasion by targeting cortactin. Oncol Rep 27: 819-824, 2012

26. Park SY, Jun JA, Jeong KJ, et al: Histone deacetylases 1, 6 and 8 are critical for invasion in breast cancer. Oncol Rep 25: 1677-1681, 2011

27. Joshi A and Cao D: TGF-beta signaling, tumor microenvironment and tumor progression: the butterfly effect. Front Biosci 15: 180-194, 2010.

28. Yu J, Ustach $\mathrm{C}$ and Kim HR: Platelet-derived growth factor signaling and human cancer. J Biochem Mol Biol 36: 49-59, 2003.

29. Lu X and Kang Y: Epidermal growth factor signalling and bone metastasis. Br J Cancer 102: 457-461, 2010.

30. Zhou HY, Pon YL and Wong AS: HGF/MET signaling in ovarian cancer. Curr Mol Med 8: 469-480, 2008.

31. Yang JD, Nakamura I and Roberts LR: The tumor microenvironment in hepatocellular carcinoma: current status and therapeutic targets. Semin Cancer Biol 21: 35-43, 2011.

32. Yang XR, Xu Y, Yu B, et al: CD24 is a novel predictor for poor prognosis of hepatocellular carcinoma after surgery. Clin Cancer Res 15: 5518-5527, 2009.

33. Inayoshi J, Ichida T, Sugitani S, et al: Gross appearance of hepatocellular carcinoma reflects E-cadherin expression and risk of early recurrence after surgical treatment. J Gastroenterol Hepatol 18: 673-677, 2003.

34. Wong CC, Wong CM, Tung EK, Man K and Ng IO: Rho-kinase 2 is frequently overexpressed in hepatocellular carcinoma and involved in tumor invasion. Hepatology 49: 1583-1594, 2009.

35. Yokomizo C, Yamaguchi $\mathrm{K}$, Itoh $\mathrm{Y}$, et al: High expression of p300 in HCC predicts shortened overall survival in association with enhanced epithelial mesenchymal transition of HCC cells. Cancer Lett 310: 140-147, 2011.

36. Miyoshi A, Kitajima Y, Kido S, et al: Snail accelerates cancer invasion by upregulating MMP expression and is associated with poor prognosis of hepatocellular carcinoma. $\mathrm{Br} \mathrm{J}$ Cancer 92: 252-258, 2005.

37. Aldana-Masangkay GI and Sakamoto KM: The role of HDAC6 in cancer. J Biomed Biotechnol 2011: 875824, 2011.

38. Grozinger CM, Hassig CA and Schreiber SL: Three proteins define a class of human histone deacetylases related to yeast Hda1p. Proc Natl Acad Sci USA 96: 4868-4873, 1999.

39. Haggarty SJ, Koeller KM, Wong JC, Grozinger CM and Schreiber SL: Domain-selective small-molecule inhibitor of histone deacetylase 6 (HDAC6)-mediated tubulin deacetylation. Proc Natl Acad Sci USA 100: 4389-4394, 2003.

40. Haggarty SJ, Koeller KM, Wong JC, Butcher RA and Schreiber SL: Multidimensional chemical genetic analysis of diversity-oriented synthesis-derived deacetylase inhibitors using cell-based assays. Chem Biol 10: 383-396, 2003.

41. Bazzaro M, Lin Z, Santillan A, et al: Ubiquitin proteasome system stress underlies synergistic killing of ovarian cancer cells by bortezomib and a novel HDAC6 inhibitor. Clin Cancer Res 14: 7340-7347, 2008.

42. Santo L, Hideshima T, Kung AL, et al: Preclinical activity, pharmacodynamic and pharmacokinetic properties of a selective HDAC6 inhibitor, ACY-1215, in combination with bortezomib in multiple myeloma. Blood 119: 2579-2589, 2012.

43. Kim HS, Vassilopoulos A, Wang RH, et al: SIRT2 maintains genome integrity and suppresses tumorigenesis through regulating APC/C activity. Cancer Cell 20: 487-499, 2011. 